Nat. Hazards Earth Syst. Sci., 17, 1461-1468, 2017

https://doi.org/10.5194/nhess-17-1461-2017

(C) Author(s) 2017. This work is distributed under

the Creative Commons Attribution 3.0 License.

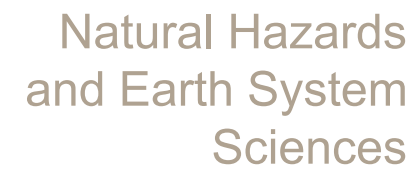

Eov

\title{
On a reported effect in ionospheric TEC around the time of the 6 April 2009 L'Aquila earthquake
}

\author{
Fabrizio Masci ${ }^{1}$, Jeremy N. Thomas ${ }^{2,3,4}$, and James A. Secan ${ }^{2}$ \\ ${ }^{1}$ Istituto Nazionale di Geofisica e Vulcanologia, L'Aquila, Italy \\ ${ }^{2}$ NorthWest Research Associates, Redmond, Washington, USA \\ ${ }^{3}$ Department of Electrical and Computer Engineering, DigiPen Institute of Technology, Redmond, Washington, USA \\ ${ }^{4}$ Department of Earth and Space Sciences, University of Washington, Seattle, Washington, USA
}

Correspondence to: Fabrizio Masci (fabrizio.masci@ingv.it)

Received: 26 January 2017 - Discussion started: 16 February 2017

Revised: 17 July 2017 - Accepted: 2 August 2017 - Published: 6 September 2017

\begin{abstract}
In a report published in Advances in Space Research, Nenovski et al. (2015) analyse ionospheric TEC (total electron content) data from GPS measurements around the time of the 6 April $2009 M_{\mathrm{w}} 6.1$ L'Aquila (Italy) earthquake. According to the authors, TEC difference (DTEC) calculated from two GPS (Global Positioning System) receivers in central Italy shows a hump-like shape (an increase followed by a decrease) during the hours just before and shortly after the main shock. They maintain that the hump-like shape is anomalous and may be related to the earthquake. We show that the DTEC increase in the hours before the shock, as well as its subsequent slow decrease, does not have any characteristic that might support a possible relationship with the earthquake. We have also conducted our own independent analysis using the same GPS data analysed by Nenovski et al. (2015). We have found a diurnal variation in DTEC time series that shows hump-like shapes like that reported by Nenovski et al. (2015) throughout the investigated period. This demonstrates that the hump-like shape in DTEC close to the time of the 6 April earthquake is not anomalous and cannot be considered a possible earthquake-related effect.
\end{abstract}

\section{Introduction}

TEC (total electron content) is a metric for measuring the ionization of the ionosphere. The phase of GPS (Global Positioning System) satellite microwave signals (1575.42 and 1227.60 MHz carrier phase frequencies) received to ground is affected by the number of electrons, known as slant TEC
(STEC), integrated over the path between the GPS satellite and the receiver. By monitoring the difference of phase between the two GPS signals, we can get the temporal changes of STEC. STEC is measured in TEC units, where $1 \mathrm{TECu}=$ $10^{16}$ electrons $\mathrm{m}^{-2}$. Equivalent-vertical TEC (VTEC) is derived from STEC, and it represents the integrated electron density in the vertical column above the GPS receiver (Komjathy et al., 2005).

Co-seismic ionospheric disturbances (CIDs) are usually observed in TEC data shortly after large $\left(M_{\mathrm{w}}>6.5\right)$ earthquakes (see Perevalova et al., 2014; Cahyadi and Heki, 2015) as the response of the ionosphere to propagating atmospheric waves excited by the vertical motion of the ground or sea level (Astafyeva et al., 2014; Jin et al., 2015; Occhipinti et al., 2013). The amplitude and duration of a CID mainly depend on the earthquake magnitude (Astafyeva et al., 2013; Cahyadi and Heki, 2015). In contrast, although there are several published papers that report ionospheric changes preceding large earthquakes (see e.g. Heki and Enomoto 2013, 2015; Liu et al., 2015), the presence of precursors in ionospheric data is still controversial within the scientific community (see Afraimovich et al., 2004; Dautermann et al., 2007; Kamogawa and Kakinami, 2013; Masci et al., 2015; Rishbeth, 2006; Thomas et al., 2017), and many reported preearthquake ionospheric effects are recently shown not to be precursors (Masci, 2012a, 2013; Masci and Thomas, 2014, 2015; Thomas et al., 2012). The ionospheric conditions are subject to various influences such as solar activity, geomagnetic activity, anthropogenic effects, and meteorological events. It also shows normal seasonal, day-to-day, 
and diurnal variations. All this makes it difficult to identify possible earthquake-related effects in the ionosphere (see e.g. Afraimovich and Astafyeva, 2008; Astafyeva and Heki, 2011) and may lead researchers to a misinterpretation of the obtained results (see e.g. Masci, 2012a, 2013; Masci and Thomas, 2015).

This paper is organized as follows. In Sect. 2, we discuss the results from the GPS-TEC analysis by Nenovski et al. (2015). Afterward, in Sect. 3 we report our own analysis of the same GPS data they used.

\section{TEC changes at time of the L'Aquila earthquake by Nenovski et al. (2015)}

Nenovski et al. (2015) investigate the occurrence of anomalous changes in VTEC (hereinafter cited as TEC) data from GPS measurement at the time of the $M_{\mathrm{w}} 6.1$ earthquake that struck the L'Aquila area on 6 April 2009 at 01:32:40 UT. The TEC data they analysed are from five GPS receivers in central Italy: UNPG (Perugia: $43.1^{\circ} \mathrm{N}, 12.4^{\circ} \mathrm{E}$ ), UNTR (Terni: $42.6^{\circ} \mathrm{N}, 12.7^{\circ} \mathrm{E}$ ), AQUI (L'Aquila: $42.4^{\circ} \mathrm{N}, 13.4^{\circ} \mathrm{E}$ ), MOSE (Rome: $41.9^{\circ} \mathrm{N}, 12.5^{\circ} \mathrm{E}$ ), and PACA (Naples: $40.9^{\circ} \mathrm{N}$, $\left.14.6^{\circ} \mathrm{E}\right)$. Refer to Fig. 1 for the location of the GPS receivers. Note that we are following the GPS community standard station naming scheme of all capitals rather than the scheme used in Nenovski et al. (2015). For example, we use UNTR rather than Untr.

Nenovski et al. (2015) report the difference of TEC data (DTEC) derived from UNTR and MOSE, the two nearest GPS receivers to the epicentral area. The two receivers are approximately 55 and $90 \mathrm{~km}$ away from L'Aquila, respectively. As stated in Nenovski et al. (2015, p. 245), collection of data at AQUI, the closest station to the earthquake epicentre, stopped for some hours starting at the time of the earthquake. They also state that, due to this gap in AQUI data, they were unable to use these data for calculating DTEC because of calibration problems.

According to Nenovski et al. (2015), TEC derived from UNTR, the closest receiver to the epicentral area, may be indicative of ionospheric disturbances on regional scale possibly related to the 6 April earthquake. For all the satellites crossing central Italy with an elevation angle EL exceeding a fixed value, they calculate the difference $\mathrm{DTEC}=\mathrm{TEC}_{\mathrm{UNTR}}-\mathrm{TEC}_{\mathrm{MOSE}}$ between TEC values that are simultaneously obtained from the GPS receivers of UNTR and MOSE. In Fig. 2 we show DTEC time series as reported by Nenovski et al. (2015) for EL $>67^{\circ}$. During 5-6 April, the DTEC time series shows an increase followed by a decrease (with a maximum at about the earthquake time) that the authors define having the hump-like shape. Conversely, the TEC difference between UNTR and UNPG (that they do not report) does not show a similar shape. Nenovski et al. (2015) conclude that the hump-like shape is anomalous and it is due to a positive TEC anomaly over the UNTR

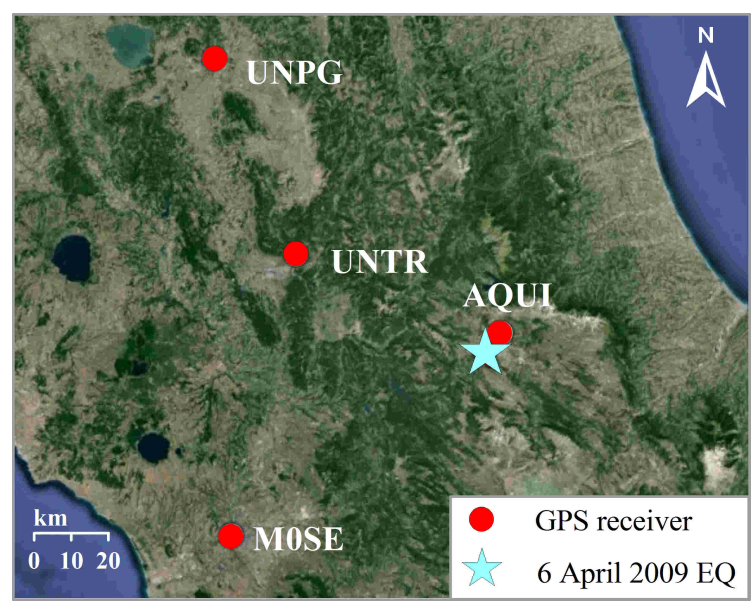

Figure 1. Four GPS receivers in central Italy whose data were analysed by Nenovski et al. (2015).

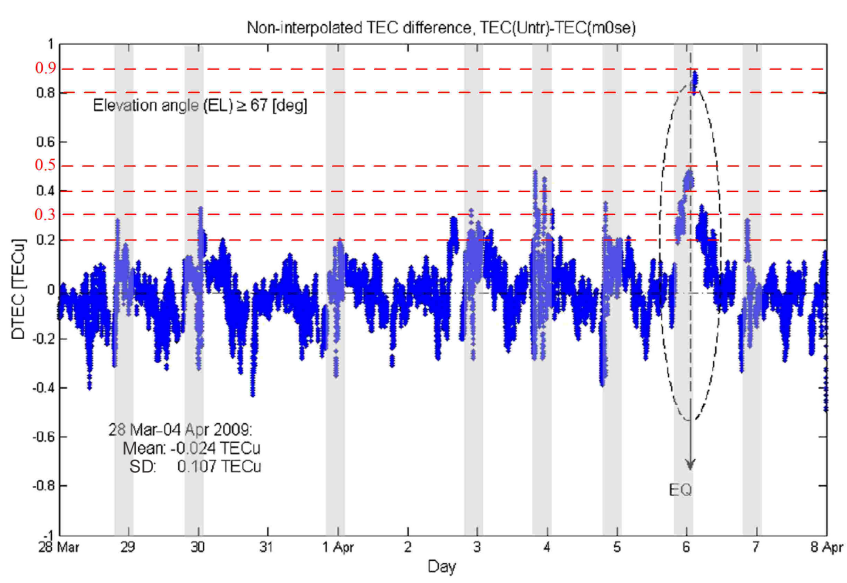

Figure 2. VTEC difference DTEC $=\mathrm{TEC}_{\mathrm{UNTR}}-\mathrm{TEC}_{\mathrm{MOSE}}$ from all satellites crossing central Italy with an elevation angle greater than $67^{\circ}$ as reported by Nenovski et al. (2015, Fig. 10a). EQ refers to the 6 April 2009 main shock. The dashed ellipse highlights the hump-like variation in DTEC during 5-6 April 2009 that according to Nenovski et al. (2015), may be related to the earthquake. Note that DTEC clearly shows a diurnal variation throughout the investigated period. The shadowed areas (that we have superimposed onto the original view) highlight DTEC maxima that, as for 5-6 April, occur in the same night period. EQ identifies the 6 April 2009 main shock.

receiver having maximum amplitude of $\sim 0.5$ TECu. Still, the positive TEC anomaly is extended up to UNPG but not to MOSE. Thus, due to the shortest distance of UNTR and UNPG from the epicentral area, they hypothesize that the hump-like shape in DTEC may be explained as related to the earthquake. We would like to point out that the humplike shape may have an interpretation different from the positive TEC anomaly over UNTR and UNPG: a negative TEC anomaly is in MOSE (the farthest GPS receiver from the epicentral area) and not in UNTR and UNPG data. In this case, 


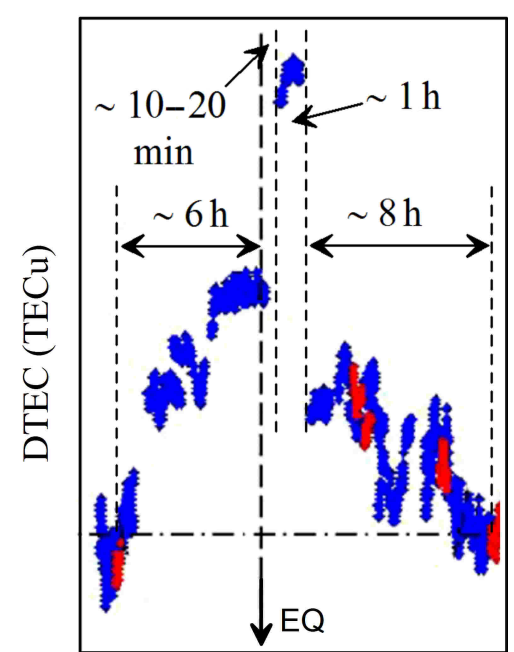

Figure 3. Enlarged view of the hump-like DTEC shape during 56 April 2009 (adapted from Nenovski et al., 2015, their Fig. 10b). Red DTEC values are from GPS satellites with elevation angles EL $>86^{\circ}$ (see Nenovski et al., 2015, for details). EQ identifies the 6 April 2009 main shock.

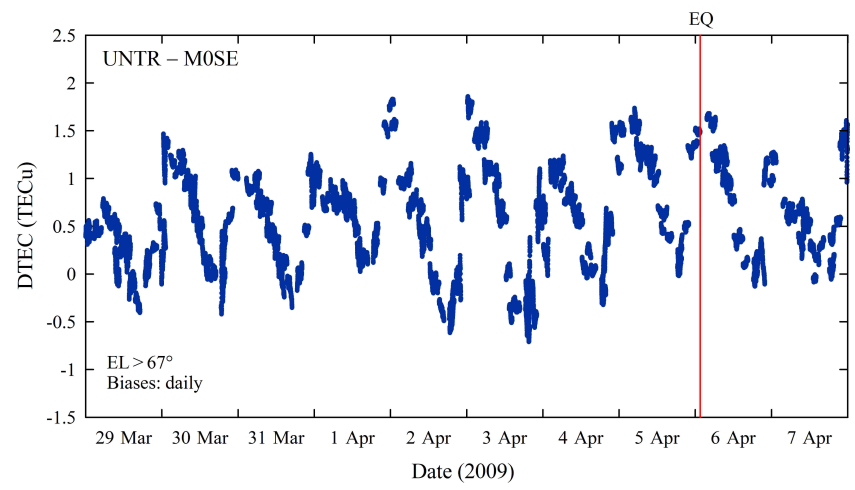

Figure 4. VTEC difference $\mathrm{DTEC}=\mathrm{TEC}_{\mathrm{UNTR}}-\mathrm{TEC}_{\mathrm{MOSE}}$ between UNTR and MOSE GPS receivers calculated using the same GPS data of Nenovski et al. (2015) from all satellites crossing central Italy with an elevation angle greater than $67^{\circ}$. The vertical red line identifies the 6 April 2009 main shock. Hump-like shapes like that reported during 5-6 April by Nenovski et al. (2015) can be seen as diurnal variation in DTEC time series. The vertical red line identifies the 6 April 2009 main shock.

could the negative anomaly in MOSE data be related to the 6 April earthquake?

In Fig. 3 we show an enlarged view of the hump-like shape in DTEC. We can see that DTEC starts to increase $\sim 6 \mathrm{~h}$ before the 6 April main shock, reaching $\sim 0.5 \mathrm{TECu}$ close to the time of the shock. A DTEC maximum having an amplitude of $\sim 0.8-0.9 \mathrm{TECu}$ can be seen to occur $\sim 10-20 \mathrm{~min}$ after the main shock, lasting about $1 \mathrm{~h}$. Nenovski et al. (2015) suggest that it may be due to a CID signature observed at UNTR. After, DTEC recovers to the pre-increase level in $\sim 8 \mathrm{~h}$.

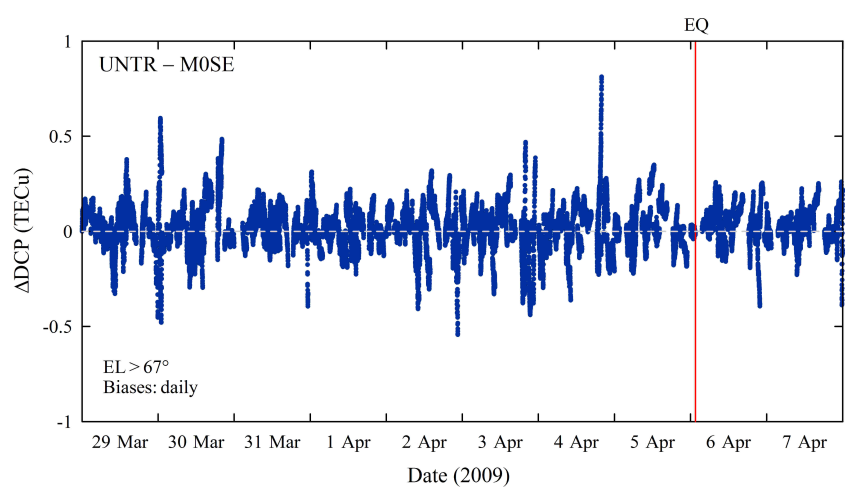

Figure 5. Differential carrier phase (DCP) difference $\triangle \mathrm{DCP}=\mathrm{DCP}_{\mathrm{UNTR}}-\mathrm{DCP}_{\mathrm{M} O S E}$ between UNTR and MOSE GPS receivers calculated using the same GPS data of Nenovski et al. (2015) from all satellites crossing central Italy with an elevation angle greater than $67^{\circ}$. The vertical red line identifies the 6 April 2009 main shock.

Our first remark concerns the possible CID, the amplitude of which is about $0.3-0.4$ TECu (see Fig. 2). This value is too high for a CID generated by a moderate $M_{\mathrm{w}}=6.1$ earthquake like that of L'Aquila. Cahyadi and Heki (2015) have shown that for moderate earthquakes the amplitude of the CID should be less than $1 \%$ of the background TEC. Thus, considering that at the time of L'Aquila earthquake the background TEC over central Italy is $\sim 5 \mathrm{TECu}$ (see Nenovski et al., 2015 Fig. 4), the amplitude of a possible CID should be less than $0.05 \mathrm{TECu}$, much less than what we can see in Fig. 2. Moreover, the $1 \mathrm{~h}$ duration of the alleged CID seems too long as well. Note that a CID effect lasting from 1 to a few hours is observed only after very large earthquakes, and it usually appears as a resonant atmospheric oscillation of about $4 \mathrm{mHz}$ (see Cahyadi and Heki, 2015) and not as a longlasting positive anomaly as shown in Nenovski et al. (2015).

Leaving aside the alleged CID effect, we do not see evidence that the hump-like behaviour in DTEC during 56 April has any characteristic that may support a possible relationship with the earthquake. Nenovski et al. (2015) report 11 days of DTEC data, from 28 March to 7 April 2009. In Fig. 2 we can see that during this period DTEC shows a diurnal variation with similar maxima to what is observed on the earthquake day. The shadowed areas (that we have superimposed onto the original view) highlight DTEC maxima that, similarly to 5-6 April, occur during the same night period. Only 2 days (31 March and 2 April) do not show a similar maximum. The amplitude of DTEC maxima usually is $\sim 0.3 \mathrm{TECu}$; on 3 April, similar to before the earthquake, the maximum amplitude of DTEC reaches $\sim 0.5 \mathrm{TECu}$. The only difference that we note during 5-6 April is a lower dispersion in DTEC data. However, this does not mean that the better-defined increase-decrease shape in DTEC may have a relationship with the earthquake. Regarding the $\sim 8 \mathrm{~h}$ slow decrease in DTEC during 6 April (the descending branch of 
the hump), while it is comparable to what we can see in the previous days, we do not see any evidence of a possible relation with the earthquake. The $\sim 8 \mathrm{~h}$ decrease cannot be interpreted as the recovery phase of an alleged CID effect as well. This is because long-lasting CIDs, the duration of which does not exceed $3-4 \mathrm{~h}$, are observed to be induced only by very powerful earthquakes, e.g. the $M_{\mathrm{w}} 9$ Tohoku-Oki earthquake of 11 March 2011 (Rolland et al., 2011).

In summary, Nenovski et al. (2015) fail to note that during the period they investigated, their analysis shows a diurnal variation in DTEC with the occurrence of maxima in the same night period during which, on 6 April, the earthquake struck the L'Aquila area. Furthermore, neither the DTEC increase during the hours prior to the earthquake nor the following slow decrease showed by Nenovski et al. (2015) on 56 April 2009 has any convincing characteristic of earthquakerelated effects.

\section{On the hypothesized generation mechanisms}

Several generation mechanisms for electric, magnetic, and ionospheric disturbances possible related to the earthquake occurrence have been proposed in scientific literature (see e.g. the review paper of Cicerone et al., 2009). However, in spite of the several published studies, many researchers are sceptical of the reliability of these mechanisms (see e.g. Dahlgren et al., 2014; Denisenko et al., 2013).

Among the mechanisms listed by Nenovski et al. (2015) (but not thoroughly investigated as possibly generation mechanisms for the hump-like shape in DTEC) there is the air ionization caused by radon emission from the Earth's crust that may disturb the global electric circuit changing the electrical resistivity of the lower atmosphere. The possible relation between changes in air radon concentration at the Earth's surface and L'Aquila seismic sequence suggested in the monograph by Giuliani and Fiorani (2009) and presented in some meetings (see e.g. Pulinets et al., 2009) is not convincing. This because radon emissions as earthquake precursors of L'Aquila earthquake have not been confirmed by further experiments (see Cigolini et al., 2015; Pitari et al., 2014). Nenovski et al. (2015), however, conclude that the spatial and temporal characteristics of the reported changes in radon concentration appear not to be in accordance with the DTEC shape observed during 5-6 April.

According to Nenovski et al. (2015), a promising generation mechanism for the hump-like shape in DTEC may be electric currents having seismogenic origin. The possible generation of electric currents prior to, or during, the earthquake is a very timely topic. Laboratory experiments have shown that electric currents are generated in dry rocks by stress loading (see e.g. Freund et al., 2006). In a recent report, Dahlgren et al. (2014) investigate the onset of electric currents in gabbro as a function of stress for both dry samples and samples saturated with fluid similar to those observed in active earthquake fault zones. Similarly to previous experiments, stress-related electric currents were observed in dry samples. On the contrary, neither transients nor stressstimulated currents were observed during several cycles of stress loading. Because the Earth's crust is fluid saturated, Dahlgren et al. (2014) conclude that significant electric currents are not expected to be generated the days before earthquakes during the slow stress accumulation in the region of earthquake nucleation; as a consequence no electric and magnetic signals are expected to be observed on the Earth's surface. Note that studies of data records from the L'Aquila area (see Biagi et al., 2010; Masci, 2012b; Masci and Di Persio, 2012; Masci and De Luca, 2013; Villante et al., 2010) have identified no anomalous magnetic or electric effects during the days or hours before and after the 6 April earthquake that might be hypothesized to have seismogenic origin. Still, in a recent report, Masci and Thomas (2016), by investigating magnetic field measurements from multiple magnetometers and seismic and strong motion records close to the earthquake epicentre, have shown that there is no evidence that might support the generation of an underground electric current in correspondence of the 6 April main shock, when the rupture occurred and the vast majority of mechanical energy was released.

\section{Our own TEC analysis}

In order to assess the significance of the signals identified by Nenovski et al. (2015), we have conducted our own independent analysis of GPS-TEC measurements in an attempt to replicate their Fig. 10a. We acquired 30 s cadence GPS measurements (RINEX-format files) for the UNTR and M0SE from the Geodetic Data Archiving Facility (GeoDAF) of Agenzia Spaziale Italiana (ASI) for March and April 2009. The group delay and carrier phase measurements in these files were used to generate time series estimates of TEC using a method developed in the ionospheric research community (Bishop et al., 1994; Mazzella et al., 2007). This method uses the SCORE (Self Calibration Of pseudo-Range Errors) technique to account for time-delay biases in both satellites and receivers and for signal multipath contamination (Bishop et al., 1996, 1997; Lunt et al., 1999). The SCORE process produces a set of corrections that account for the sum effect of time-delay biases and multipath effects for each receiversatellite pair for each day. It should be noted that although we will be working with TEC differences in this paper, the SCORE calibrations do not cancel out in the differencing process. The biases estimated by the SCORE process include the effects of time-delay biases in the satellite transmitters and in the receiving hardware (from the antenna to the frontend processing within the receiver), as well as multipath contamination. While the time-delay biases in the satellite transmitters will be the same for all stations, the other components of the biases are not only station dependent. The re- 
ceiving hardware biases can also vary diurnally due to factors such as the local ambient temperature. Accepted values for the uncertainty in the absolute TEC due to uncertainties in the bias values are on the order of 1 to $2 \mathrm{TECu}$. For instance, Ciraolo et al. (2007) quote a minimum uncertainty of 1.4 TECu in a study of observed data, whereas a second study based on analysis of simulated data (Ciraolo, 2009) shows uncertainties from 0.5 to $4.0 \mathrm{TECu}$ depending on latitude. These studies also show that the uncertainties in the absolute TEC measurements are uncorrelated between two receivers, even if closely spaced. Note that these uncertainties are larger than the signals identified as earthquake-related by Nenovski et al. (2015).

Our first attempt to replicate Fig. 10a by Nenovski et al. (2015) is shown in Fig. 4, which is a plot of the difference DTEC $=$ TEC $_{\text {UNTR }}-$ TEC $_{\text {MOSE }}$ between VTEC at stations UNTR and MOSE for measurements with elevation angles greater than $67^{\circ}$. The VTEC estimates made use of SCORE-derived biases and multipath for each station day (10 correction sets per station). A strong diurnal variation in DTEC is very clear in this plot, with values ranging from -0.7 to $+1.9 \mathrm{TECu}$. No anomalous changes in this variation are seen prior to or after the time of the earthquake. Also, no evident CID effect can be seen. Hump-like shapes like that reported during 5-6 April by Nenovski et al. (2015) can be seen throughout the investigated period as diurnal variation in DTEC time series with maxima in the same night period. This demonstrates that the hump-like shape in DTEC reported in Nenovski et al. (2015) at the time of L'Aquila earthquake is not significant, and therefore it cannot be associated with the earthquake.

Since there are differences between our Figs. 4 and 10a by Nenovski et al. (2015), we also take a different approach as shown in Fig. 5. Using the same data set as used to generate Fig. 4, we find the difference in the differential carrier phase (DCP) between UNTR and MOSE $\left(\triangle \mathrm{DCP}=\mathrm{DCP}_{\mathrm{UNTR}}-\mathrm{DCP}_{\mathrm{MOSE}}\right)$, also for elevation angles great than $67^{\circ}$. In order to remove the effects of the unknown number of phase cycles between the satellite transmitters and the ground receivers, the DCP at each station is offset to zero at the first point in the time series where the elevation angle exceeded $67^{\circ}$ prior to calculating the difference between the stations. Note that these data do not include the SCORE correction factors, nor have then been modified to make them into an equivalent-vertical estimate. The diurnal signal evident in Fig. 4 has disappeared in Fig. 5. However, as in Fig. 4, there is no evident anomalous change in the $\triangle \mathrm{DCP}$ time series, and no hump-like shape can be seen during the hours around the earthquake time.

During the review process of our paper, the main criticism was regarding the algorithm we used for obtaining VTEC data. Even though Nenovski et al. (2015) do not provide details on the software they used for calculating VTEC or cite any reference, it has been claimed that no one could replicate the results presented in Nenovski et al. (2015) without us- ing their "special" software for VTEC. This software would be the only analysis procedure that gives reliable results for the identification of precursory signals in VTEC time series. We would like to point out that there is no substantiated study that supports the statement that one method (including that of Nenovski et al., 2015) is better than any other for precursory studies in VTEC. Note that Fig. 10a of Nenovski et al. (2015) shows a diurnal variation in DTEC similar to that reported in our Fig. 4. The only difference is that the diurnal variation in DTEC is more evident in our figure than in the figure of Nenovski et al. (2015). Our analysis has put in evidence betterdefined hump-like shapes throughout the investigated period (including the hump-like shape of 5-6 April), showing that the analysis procedure adopted by Nenovski et al. (2015) has lead the authors to a not very careful interpretation of data.

We believe that the diurnal variation evidence in our Fig. 4, as well as that we can see in Nenovski et al. (2015, Fig. 10a), is not an ionospheric signal but rather an artefact due to an assumption made in the calibration processes and that the biases being solved for are constant over the time of the calibration analysis $(24 \mathrm{~h})$. While this assumption is good for the time-delay biases at the satellite, it is not as good for the bias imposed at the receive end (from the antenna to the correlator processing within the GPS receiver). As described in Ciraolo et al. (2007), the time delay on the ground segment can be effected by the ambient diurnal temperature variation, which will be different at different locations and for different equipment set-ups. Thus, the diurnal variation in Fig. 4, which can be seen does not change much across the time of the earthquake, is due to a different diurnal variation in the receiver-end time delay at the two stations being differenced (UNTR and MOSE in our case).

In summary, we believe that we have replicated the results showed by Nenovski et al. (2015) in their Fig. 10a, and we have also highlighted uncertainties in how they processed and analysed GPS data. In our analysis of both the (absolute) VTEC and the (relative) slant-path DCP measurements derived from GPS measurements taken at UNTR and MOSE around the time of the L'Aquila earthquake, we find no evidence for anomalous signals during the investigated period.

\section{Conclusion}

We do not see evidence that the hump-like shape in DTEC shown by Nenovski et al. (2015) during 5-6 April 2009 may be considered an actual earthquake-related phenomenon. The hypothesis that the DTEC increase during the hours prior to the earthquake, as well as the following slow decrease, may have seismogenic origin is not supported by evidence. The DTEC time series reported by Nenovski et al. (2015) shows a diurnal variation with maxima that occur in the same night period, suggesting that the hump-like shape during 5-6 April 2009 is not anomalous and its correspondence with the earthquake is just a coincidence. This is supported by our own in- 
dependent analysis of the same GPS data analysed by Nenovski et al. (2015). Our DTEC calculation shows that humplike shapes like that reported by Nenovski et al. (2015) during 5-6 April can be seen as diurnal variation of DTEC time series throughout the investigated period. Further analysis of the difference in the differential carrier phase between UNTR and MOSE has identified no anomalous change during the investigated period, and no hump-like shape has been found around the time of the earthquake.

The search for precursors is aimed toward the development of prediction capabilities earthquakes. In spite of intensive efforts using different data analysis techniques and the publication of numerous papers reporting alleged precursors, until now there has been no method for predicting earthquakes. However, in the scientific community, earthquake prediction is a controversial topic, with opinions ranging from impossible, to perhaps possible in the future, to possible in the near future with precursors occurring on a regular basis. Thus, the claim of having identified precursory signals of the earthquake is an extraordinary statement that should require extraordinary evidence. We have shown that the attempt of Nenovski et al. (2015) to identify the precursor of L'Aquila earthquake is not sufficient to support an extraordinary claim.

Data availability. GPS RINEX-format files are available at the Geodetic Data Archiving Facility of Agenzia Spaziale Italiana (ftp: //geodaf.mt.asi.it/GEOD/GPSD/RINEX/2009/).

Competing interests. The authors declare that they have no conflict of interest.

Acknowledgements. We thank the editor and three anonymous referees for constructive reviews. We thank Agenzia Spaziale Italiana for providing the RINEX-format GPS files.

Edited by: Filippos Vallianatos

Reviewed by: three anonymous referees

\section{References}

Afraimovich, E. L. and Astafyeva, E. I.: TEC anomalies - local TEC changes prior to earthquakes or TEC response to solar and geomagnetic activity changes?, Earth Planets Space, 60, 961-966, https://doi.org/10.1186/BF03352851, 2008.

Afraimovich, E. L., Astafyeva, E. I., Gokhberg, M. B., Lapshin, V. M., Permyakova, V. E., Steblov, G. M., and Shalimov, S. L.: Variations of the total electron content in the ionosphere from GPS data recorded during the Hector Mine earthquake of October 16, 1999, California, Russian Journal of Earth Sciences, 6, 339-354, https://doi.org/10.2205/2004ES000155, 2004.

Agenzia Spaziale Italiana: RINEX-format GPS files, ftp://geodaf. mt.asi.it/GEOD/GPSD/RINEX/2009/ (last access: 26 October 2016), 2012.
Astafyeva, E. and Heki, K.: Vertical TEC over seismically active region during low solar activity, J. Atmos. Sol.-Terr. Phy., 73, 1643-1652, https://doi.org/10.1016/j.jastp.2011.02.020, 2011.

Astafyeva, E., Shalimov, S., Olshanskaya, E., and Lognonné, P.: Ionospheric response to earthquakes of different magnitudes: Larger quakes perturb the ionosphere stronger and longer, Geophys. Res. Lett., 40, 1675-1681, https://doi.org/10.1002/grl.50398, 2013.

Astafyeva, E., Rolland, L. M., and Sladen, A.: Strike-slip earthquakes can also be detected in the ionosphere, Earth Planet Sc. Lett., 405, 180-193, https://doi.org/10.1016/j.eps1.2014.08.024, 2014.

Biagi, P. F., Castellana, L., Maggipinto, T., Loiacono, D., Schiavulli, L., Ligonzo, T., Fiore, M., Suciu, E., and Ermini, A.: Brief communication "A pre seismic radio anomaly revealed in the area where the Abruzzo earthquake $(M=6.3)$ occurred on 6 April 2009”, Nat. Hazards Earth Syst. Sci., 10, 215-216, https://doi.org/10.5194/nhess-10-215-2010, 2010.

Bishop, G., Walsh, D., Daly, P., Mazzella, A., and Holland, E.: Analysis of temporal stability of GPS and GLONASS group delay correction terms seen in various sets of ionospheric delay data, in: Proceedings of ION GPS-94, The Institute of Navigation, Washington, D.C., 1653-1661, 1994.

Bishop, G., Mazzella, A., Holland, E., and Rao, S.: Algorithms that use the ionosphere to control GPS errors, in: Proceedings of the IEEE 1996 Position Location and Navigation Symposium (PLANS), IEEE, Atlanta, GA, 145-152, 1996.

Bishop, G., Mazzella, A., Rao, S., Batchelor, A., Fleming, P., Lunt, N., and Kersley, L.: Validations of the SCORE process, in: Proceedings of the 1997 National Technical Meeting of the Institute of Navigation, 14-16 January 1997, Santa Monica, CA, 289296, 1997.

Cahyadi, M. N. and Heki, K.: Coseismic ionospheric disturbance of the large strike-slip earthquakes in North Sumatra in 2012: Mw dependence of the disturbance amplitudes, Geophys. J. Int., 200, 116-129, https://doi.org/10.1093/gji/ggu343, 2015.

Cicerone, R. D., Ebel, J. E., and Britton, J.: A systematic compilation of earthquake precursors, Tectonophysics, 476, 371-396, https://doi.org/10.1016/j.tecto.2009.06.008, 2009.

Cigolini, C., Laiolo, M., and Coppola, D.: The LVD signals during the early-mid stages of the L'Aquila seismic sequence and the radon signature of some aftershocks of moderate magnitude, J. Environon. Radioactiv., 139, 56-65, https://doi.org/10.1016/j.jenvrad.2014.09.017, 2015.

Ciraolo, L.: TEC calibration techniques: Single-station estimation of arc offsets, in: Satellite Navigation Science and Technology for Africa, 23 March-9 April 2009, Trieste, Italy, 2009.

Ciraolo, L., Azpilicueta, F., Brunini, C., Meza, A., and Radicella, S. M.: Calibration errors on experimental slant total electron content (TEC) determined with GPS, J. Geodesy, 81, 111-120, https://doi.org/10.1007/s00190-006-0093-1, 2007.

Dahlgren, R. P., Johnston, M. J. S., Vanderbilt, V. C., and Nakaba, R. N.: Comparison of the Stress-Stimulated Current of Dry and Fluid-Saturated Gabbro Samples, B. Seismol. Soc. Am., 104, 2662-2672, https://doi.org/10.1785/0120140144, 2014.

Dautermann, T., Calais, E., Haase, J., and Garrison, J.: Investigation of ionospheric electron content variations before earthquakes in southern California, 2003-2004, J. Geophys. Res., 112, B02106, https://doi.org/10.1029/2006JB004447, 2007. 
Denisenko, V. V., Ampferer, M., Pomozov, E. V., Kitaev, A. V., Hausleitner, W., Stangl, G., and Biernat, H. K.: On electric field penetration from ground into the ionosphere, J. Atmos. Sol.-Terr. Phy., 102, 341-353, https://doi.org/10.1016/j.jastp.2013.05.019, 2013.

Freund, F., Takeuchi, A., and Lau, B.: Electric currents streaming out of stressed igneous rocks - a step towards understanding preearthquake low frequency EM emissions, Phys. Chem. Earth, 31, 389-396, https://doi.org/10.1016/j.pce.2006.02.027, 2006.

Giuliani, G. and Fiorani, A.: L'Aquila 2009 la mia verità sul terremoto, Castelvecchi Editore, Rome, 166 pp., 2009.

Heki, K. and Enomoto, Y.: Preseismic ionospheric electron enhancements revisited, J. Geophys. Res.-Space, 118, 6618-6626, https://doi.org/10.1002/jgra.50578, 2013.

Heki, K. and Enomoto, Y.: $M_{w}$ dependence of the preseismic ionospheric electron enhancements, J. Geophys. Res.-Space, 120, 7006-7020, https://doi.org/10.1002/2015JA021353, 2015.

Jin, S., Occhipinti, G., and Jin, R.: GNSS ionospheric seismology: Recent observation evidences and characteristics, Earth-Sci. Rev. 147, 54-64, https://doi.org/10.1016/j.earscirev.2015.05.003, 2015.

Kamogawa, M. and Kakinami, Y.: Is an ionospheric electron enhancement preceding the 2011 Tohoku-Oki earthquake a precursor?, J. Geophys. Res.-Space, 118, 1751-1754, https://doi.org/10.1002/jgra.50118, 2013.

Komjathy, A., Sparks, L., Wilson, B., and Mannucci, A. J.: Automated daily processing of more than 1000 ground-based GPS receivers to study intense ionospheric storms, Radio Sci., 40, RS6006, https://doi.org/10.1029/2005RS003279, 2005.

Liu, J. Y., Chen, Y. I., Huang, C. C., Parrot, M., Shen, X. H., Pulinets, S. A., Yang, Q. S., and Ho, Y. Y.: A spatial analysis on seismo-ionospheric anomalies observed by DEMETER during the 2008 M8.0 Wenchuan earthquake, J. Asian Earth Sci., 114, 414-419, https://doi.org/10.1016/j.jseaes.2015.06.012, 2015.

Lunt, N., Kersley, L., Bishop, G. J., Mazzella Jr., A. J., and Bailey, G. J.: The effects of the protonosphere on the estimation of GPS total electron content: Validation using model simulations, Radio Sci., 34, 1261-1271, https://doi.org/10.1029/1999RS900043, 1999.

Masci, F.: The study of ionospheric anomalies in Japan area during $1998-2010$ by Kon et al.: An inaccurate claim of earthquake-related signatures?, J. Asian Earth Sci., 57, 1-5, https://doi.org/10.1016/j.jseaes.2012.06.009, 2012a.

Masci, F.: Comment on "Ultra Low Frequency (ULF) European multi station magnetic field analysis before and during the 2009 earthquake at L'Aquila regarding regional geotechnical information" by Prattes et al. (2011), Nat. Hazards Earth Syst. Sci., 12, 1717-1719, https://doi.org/10.5194/nhess-12-1717-2012, 2012 b.

Masci, F.: Brief communication "Further comments on the ionospheric precursor of the 1999 Hector Mine earthquake", Nat. Hazards Earth Syst. Sci., 13, 193196,https://doi.org/10.5194/nhess-13-193-2013, 2013.

Masci, F. and Di Persio, M.: Retrospective investigation of geomagnetic field time-series during the 2009 L'Aquila seismic sequence, Tectonophysics, 530-531, 310-317, https://doi.org/10.1016/j.tecto.2012.01.008, 2012.
Masci, F. and De Luca, G.: Some comments on the potential seismogenic origin of magnetic disturbances observed by $\mathrm{Di}$ Lorenzo et al. (2011) close to the time of the 6 April 2009 L'Aquila earthquake, Nat. Hazards Earth Syst. Sci., 13, 13131319, https://doi.org/10.5194/nhess-13-1313-2013, 2013.

Masci, F. and Thomas, J. N.: Comment on "Temporal and spatial precursors in ionospheric total electron content of the 16 October $1999 M_{w} 7.1$ Hector Mine earthquake" by $\mathrm{Su}$ et al. (2013), J. Geophys. Res.-Space, 119, 6994-6997, https://doi.org/10.1002/2014JA019896, 2014.

Masci, F. and Thomas, J. N.: On the reliability of the Spatial Scintillation Index to identify ionospheric precursors of earthquakes, Radio Sci., 50, 745-753, https://doi.org/10.1002/2015RS005734, 2015.

Masci, F. and Thomas, J. N.: Evidence of underground electric current generation during the 2009 L'Aquila earthquake: Real or instrumental?. Geophys. Res. Lett., 43, 6153-6161, https://doi.org/10.1002/2016GL069759, 2016.

Masci, F., Thomas, J. N., Villani, F., Secan, J. A., and Rivera, N.: On the onset of ionospheric precursors $40 \mathrm{~min}$ before strong earthquakes, J. Geophys. Res.-Space, 120, 1383-1393, https://doi.org/10.1002/2014JA020822, 2015.

Mazzella, A. J., Rao, G. S., Bailey, G. J., Bishop, G. J., and Tsai, L. C.: GPS determinations of plasmasphere TEC, in: Proceedings of the International Beacon Satellite Symposium 2007, edited by: Doherty, P., Boston College, Boston, Mass, 2007.

Nenovski, P. I., Pezzopane, M., Ciraolo, L., Vellante, M., Villante, U., and De Lauretis, M.: Local changes in the total electron content immediately before the 2009 Abruzzo earthquake, Adv. Space Res., 55, 243-258, https://doi.org/10.1016/j.asr.2014.09.029, 2015.

Occhipinti, G., Rolland, L., Lognonné, P., and Watada, S.: From Sumatra 2004 to Tohoku-Oki 2011: The systematic GPS detection of the ionospheric signature induced by tsunamigenic earthquakes, J. Geophys. Res.-Space, 118, 3626-3636, https://doi.org/10.1002/jgra.50322, 2013.

Perevalova, N. P., Sankov, V. A., Astafyeva, E. I., and Zhupitayaeva, A. S.: Threshold magnitude for ionospheric TEC response to earthquake, J. Atmos. Sol.-Terr. Phy., 108, 77-90, https://doi.org/10.1016/j.jastp.2013.12.014, 2014.

Pitari, G., Coppari, E., De Luca, N., and Di Carlo, P.: Observations and box model analysis of radon-222 in the atmospheric surface layer at L'Aquila, Italy: March 2009 case study, Environmental Earth Sciences, 71, 2353-2359, https://doi.org/10.1007/s12665013-2635-1, 2014.

Pulinets, S. A., Ouzounov, D. P., Giuliani, G., Ciraolo, L., and Taylor, P. T.: Atmosphere and radon activities observed prior to Abruzzo M6.3 earthquake of April 6, 2009, AGU Fall Meeting Abstracts, \#U14A-07, 2009.

Rishbeth, H.: Ionoquakes: Earthquake precursors in the ionosphere?, Eos T. Am. Geophys. Un., 87, 316, https://doi.org/10.1029/2006EO320008, 2006.

Rolland, L., Lognonné, P., Astafyeva, E., Kherani, A., Kobayashi, N., Mann, M., and Munekane, H.: The resonant response of the ionosphere imaged after the 2011 Tohoku-Oki earthquake, Earth Planets Space, 63, 853-857, https://doi.org/10.5047/eps.2011.06.020, 2011. 
Thomas, J. N., Love, J. J., Komjathy, A., Verkhoglyadova, O. P., Butala, M., and Rivera, N.: On the reported ionospheric precursor of the 1999 Hector Mine, California earthquake, Geophys. Res. Lett., 39, L06302, https://doi.org/10.1029/2012GL051022, 2012.

Thomas, J. N., Huard, J., and Masci, F.: A statistical study of global ionospheric map total electron content changes prior to occurrences of $M \geq 6.0$ earthquakes during 2000-2014, J. Geophys. Res.-Space, 122, 2151-2161, https://doi.org/10.1002/2016JA023652, 2017.
Villante, U., De Lauretis, M., De Paulis, C., Francia, P., Piancatelli, A., Pietropaolo, E., Vellante, M., Meloni, A., Palangio, P., Schwingenschuh, K., Prattes, G., Magnes, W., and Nenovski, P.: The 6 April 2009 earthquake at L'Aquila: a preliminary analysis of magnetic field measurements, Nat. Hazards Earth Syst. Sci., 10, 203-214, https://doi.org/10.5194/nhess-10-203-2010, 2010. 